\title{
Reduced Capillary Density in the Prefrontal Cortex in Schizophrenia
}

\author{
Natalya Uranova ${ }^{1, *}$, Ivetta Zimina ${ }^{1}$, Olga Vikhreva ${ }^{1}$, Valentina Rachmanova $^{1}$, Anna Klintsova ${ }^{2}$, Diana Orlovskaya ${ }^{1}$ \\ ${ }^{1}$ Laboratory of Clinical Neuropathology, Mental Health Research Center of Russian Academy of Medical Sciences, Moscow, Russia \\ ${ }^{2}$ Beckman Institute, University of Illinois, Urbana-Champaign, Illinois, USA \\ *Corresponding author: uranovan@gmail.com
}

Received December 18, 2012; Revised May 16, 2013; Accepted May 17, 2013

\begin{abstract}
Neuroimaging studies have shown that the core symptoms of schizophrenia are associated with local changes of cerebral blood flow, particularly in the frontal cortex. Previously we reported ultrastructural damage of capillaries in the upper layers of the prefrontal cortex, Brodmann's area (BA) 10 and in the visual cortex, BA 17 in schizophrenia. An electron microscopic morphometric study was performed to estimate capillary area density $(\mathrm{N}$ cap $/ \mathrm{mm}^{2}$ ) in two upper layers of the prefrontal and visual cortices in 26 cases of schizophrenia and 26 normal controls. Capillary area density was lower in the prefrontal cortex in the schizophrenia group $(-24 \%, \mathrm{p}<0.001)$ and in the subgroup of schizophrenia with predominantly negative symptoms $(\mathrm{n}=12,-35 \%, \mathrm{p}<0.001)$ as compared to controls. Group and subgroup differences were absent in the visual cortex. Dysfunction of neocortical microvasculature in schizophrenia is related to region-specific capillary deficiency in the prefrontal cortex. These changes might contribute to the lowered blood flow, reduced glucose metabolic rates, resting hypofrontality and hypoactivation reported in the prefrontal cortex of patients with schizophrenia.
\end{abstract}

Keywords: schizophrenia, capillary, electron microscopy, morphometry, prefrontal cortex, visual cortex

\section{Introduction}

Neuroimaging studies have consistently shown that diverse symptoms of schizophrenia are associated with local changes of cerebral blood flow, particularly in the frontal cortex. Frontal regional blood flow was not increased while performing cognitive tests in patients with schizophrenia as compared to normal controls $[1,2,3,4]$. Decreased blood flow [5] and glucose metabolic rates $[6,7]$, as well as resting hypofrontality [8] and hypoperfusion $[9,10]$ have been reported in the prefrontal cortex in patients with schizophrenia. Reduced frontal blood flow is associated with negative symptoms of schizophrenia [11,12,13,14]. Hanson and Gottesman [15] suggested that abnormalities of blood flow might lead to altered neuronal-glial relationships resulting in neuronal dysfunction and psychopathology. However, it has remained uncertain whether these changes are related to the abnormalities of microcirculation.

Brain microcircuitry might be abnormal in schizophrenia. Though mean capillary length density was not changed in the prefrontal cortex (BA9) [16] or subcortical brain structures [17] in schizophrenia, decreased numbers of capillary loops were detected by biomicroscopy of the bulbar conjunctiva and capillaroscopy in schizophrenia patients [18]. Ultrastructural alterations of capillaries in human embryos from schizophrenia mothers have been reported previously [19]. Also, an atypical simplified angioarchitecture and abnormal arborization of the brain vessels [20], decreased GFAP labeling of astrocytes adjacent to blood vessels [21] and lowered number of pericapillary oligodendrocytes [22] have been described in postmortem prefrontal cortex in schizophrenia. Analysis of endothelial cells showed differences in gene expression between schizophrenics and controls [23]. Decreased VEGF mRNA expression has been recently reported in the dorsolateral prefrontal cortex of schizophrenia subjects [24].

Previously we reported ultrastructural damage of capillaries in postmortem prefrontal and visual cortices in subjects diagnosed with schizophrenia [25]. However, it has remained unclear whether capillary density is affected in schizophrenia. We hypothesized that subjects with schizophrenia would show a capillary deficiency in the neocortex.

The aim of the current study was to estimate capillary area density in the upper layers of the prefrontal and visual cortices in schizophrenia and normal controls using quantitative electron microscopy.

\section{Materials and Methods}

\subsection{Subjects and Tissue}

Brains were collected from the Mental Health Research Center (MHRC, Moscow, Russian Federation) within a short postmortem delay (4-8 hours). Ethical considerations in obtaining and using human autopsy material were in accordance with the rules of the Ethic Committee of the MHRC, Russian Academy of Medical Sciences. Twentysix (26) subjects with schizophrenia and 26 normal control subjects matched by age and postmortem delay were used.

Demographic and clinical data are provided in Table 1. 
Table 1. Demographic and clinical data

\begin{tabular}{|c|c|c|c|c|c|c|c|c|}
\hline & & $\begin{array}{l}\mathrm{N} \text { per } \\
\text { group }\end{array}$ & Gender & Age (years) & PMI(hours) & $\begin{array}{c}\text { Duration of } \\
\text { disease } \\
\text { (years) }\end{array}$ & $\begin{array}{c}\text { Age at onset } \\
\text { of disease } \\
\text { (years) }\end{array}$ & $\begin{array}{l}\text { Neuroleptic } \\
\text { medication }\end{array}$ \\
\hline & & & & \multicolumn{5}{|c|}{$($ Mean \pm SD) } \\
\hline \multicolumn{2}{|c|}{ Controls } & 26 & $5 \mathrm{~F} / 21 \mathrm{M}$ & $52.3 \pm 14.8$ & $5.5 \pm 0.9$ & & & \\
\hline \multicolumn{2}{|c|}{ Schizophrenia } & 26 & $15 \mathrm{~F} / 11 \mathrm{M}$ & $53.5 \pm 16.2$ & $6.0 \pm 2.1$ & $20.6 \pm 13.8$ & $33.3 \pm 15.5$ & $79.35 \pm 104.2$ \\
\hline \multirow{4}{*}{ 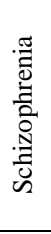 } & SPNS & 12 & $5 \mathrm{~F} / 7 \mathrm{M}$ & $52.5 \pm 15.7$ & $5.6 \pm 1.5$ & $21.6 \pm 14.9$ & $32.2 \pm 15.3$ & $112.4 \pm 135.0$ \\
\hline & SPPS & 14 & $10 \mathrm{~F} / 4 \mathrm{M}$ & $54.3 \pm 17.2$ & $6.3 \pm 2.6$ & $19.8 \pm 13.3$ & $34.2 \pm 16.3$ & $54.6 \pm 70.2$ \\
\hline & $\begin{array}{c}\text { Nonparanoid } \\
\text { schizophrenia }\end{array}$ & 9 & $4 \mathrm{M} / 5 \mathrm{~F}$ & $44.1 \pm 16.3$ & $5.4 \pm 3.1$ & $13.0 \pm 14.0$ & $31.2 \pm 16.2$ & $21.4 \pm 36.5$ \\
\hline & $\begin{array}{c}\text { Paranoid } \\
\text { schizophrenia }\end{array}$ & 17 & $7 \mathrm{M} / 10 \mathrm{~F}$ & $58.4 \pm 14.3$ & $6.3 \pm 1.5$ & $25.2 \pm 11.9$ & $34.5 \pm 15.6$ & $108.3 \pm 115.7$ \\
\hline \multirow{2}{*}{\multicolumn{2}{|c|}{ Causes of death }} & Controls & \multicolumn{6}{|c|}{ Cardiovascular disease, myocardial infarction, blood vessel rupture, pneumonia } \\
\hline & & $\begin{array}{l}\text { Schizo- } \\
\text { phrenia }\end{array}$ & \multicolumn{6}{|c|}{ Cardiovascular disease, myocardial infarction, pulmonary embolism, aspiration asphyxia } \\
\hline
\end{tabular}

SPNS - schizophrenia with predominantly negative symptoms. SPPS - schizophrenia with predominantly positive symptoms. Neuroleptic medication for one year prior to death is expressed as CPZ-equivalents, $\mathrm{mg}$.

Clinical records were obtained and both ICD-10 and DSM-IV diagnoses were made by MHRC psychiatrists. The Scale for the Assessment of Negative Symptoms (SANS) and the Scale for the Assessment of Positive Symptoms (SAPS) were used to rate negative and positive symptoms during the last hospitalization of schizophrenia subjects. Summary scores of negative and positive symptoms were determined on the basis of the ratio of the percentage of negative and positive scores. 12 cases with predominantly negative symptoms, 14 cases with predominantly positive symptoms and 26 normal control cases were studied. The schizophrenia group included 17 cases of chronic paranoid schizophrenia and 9 cases of other types of chronic schizophrenia: undifferentiated schizophrenia $(n=4)$, catatonic schizophrenia $(n=2)$, residual $(\mathrm{n}=2)$, unspecified schizophrenia $(\mathrm{n}=1)$ (nonparanoid schizophrenia).

Cases were coded, and the researchers were blind to patient diagnosis. For electron microscopy for each case, 10 small serial tissue samples containing grey matter of the central part of the prefrontal cortex (BA10) and of the visual cortex (BA17) from the left hemisphere were obtained in a plane vertical to the pial surface. The tissue samples were fixed in a mixture of $2.5 \%$ glutaraldehyde and $4 \%$ paraphormaldehyde in $0.1 \mathrm{M}$ phosphate buffer for one week. Then, tissue pieces were postfixed in $1 \%$ osmium tetroxide for one hour, stained with uranyl acetate for one hour, dehydrated in ethanol series and embedded in Araldit epoxy resin. Three prefrontal cortex tissue blocks and three visual cortex tissue blocks were randomly sampled. Sections were cut using an Reichert ultramicrotome, and $1 \mu \mathrm{m}$ thick sections stained with toluidine blue were used for orientation in cortical layers. Small pyramids were trimmed on the two upper layers (containing polymorphous cells and located above layer 3 containing pyramidal neurons), and ultrathin sections were cut at $60 \mathrm{~nm}$. We have chosen these layers on the basis of the previous evidence for ultrastructural damage of capillaries in the upper layers of the prefrontal and visual cortices in schizophrenia [25]. Ultrathin sections were taken and mounted onto Formvar/carbon coated slot-type copper grids, counterstained with uranyl acetate and lead citrate and examined in a Philips EM 420 electron microscope.

\subsection{Quantitative Data Collection}

Three prefrontal cortex tissue blocks and three visual cortex tissue blocks examined per subject. Capillary area density was estimated in two upper layers of the prefrontal and visual cortices in the control and schizophrenia groups. Capillaries were identified according to criteria described by Peters [26]. Capillary density in the prefrontal cortex was estimated within a tissue area of on average $84,700 \mu \mathrm{m}^{2}$ per brain for the control group and $84,400 \mu \mathrm{m}^{2}$ per brain for the schizophrenia group. The tissue area examined in the visual cortex was on average $88,000 \mu \mathrm{m}^{2}$ per brain for the control group and $101,300 \mu \mathrm{m}^{2}$ per brain for the schizophrenia group. The number of all capillary profiles $<10 \mu \mathrm{m}$ in diameter were counted using 4,000x magnification. Mean number of capillaries (mean \pm SD) per brain calculated in the prefrontal cortex was $20.3 \pm 4.3$ for the control group and $15.6 \pm 3.4$ for the schizophrenia group. In the visual cortex the mean number of capillaries per brain was $15.5 \pm 4.7$ for the control group and $17.9 \pm$ 5.8 for the schizophrenia group. After adjusting for magnification, the number of capillaries per unit tissue area was estimated by dividing the total number of capillary profiles counted by the total area examined. Then the capillary area density was estimated as the number of capillaries per $1 \mathrm{~mm}^{2}$.

\subsection{Statistical Analysis}

Statistical analysis was performed using the STATISTICA software package for Windows (StatSoft. Inc, Tusla, OK, USA) to test the hypothesis that schizophrenia subjects have deficient capillaries in the neocortex. Capillary area density between the groups was analyzed. In addition, the control group was compared with two sets of clinical subgroups: cases with predominantly positive or negative symptoms and cases of paranoid or nonparanoid schizophrenia. Group comparisons were made using one-way ANOVA. Differences between the control group and different clinical subgroups were examined using one-way ANOVA with the control group and each of two sets of clinical subgroups, followed by post hoc test (Duncan's test, $\alpha<0.05)$ using the Bonferroni correction. Correlational analysis was performed for the control and 
schizophrenia group to examine the effects of postmortem delay, age, age at onset of disease, duration of disease, medication (expressed as chlorpromazine equivalents according to Davis [27]). A normal distribution of the data by Kolmogorov-Smirnov tests was obtained, so the Pearson correlation coefficient was used. Gender effects were analyzed using a two-way ANOVA.

\section{Results}

Figure 1 illustrates the electron microscopic appearance of blood capillaries in the prefrontal cortex from control and schizophrenia brains. Characteristic thickening of capillary basement membrane and swelling of pericapillary astrocytic end-feet were observed in the schizophrenia subjects (Figure 1B) in contrast to the control subjects (Figure 1A). There was no correlation between capillary area density and either age or postmortem interval. Means \pm SEM of capillary area density for control group, schizophrenia group and schizophrenia subgroups are given in Table 2. Differences between the control group and schizophrenia group and subgroups are given in Figure 2. One-way ANOVA demonstrated a reduction in the capillary area density by $24 \%$ in the schizophrenia group as compared to the control group in the prefrontal cortex: $(\mathrm{F}=12.53$, df $=$ $1,50, \mathrm{p}=.0009$ ) (Figure 2).

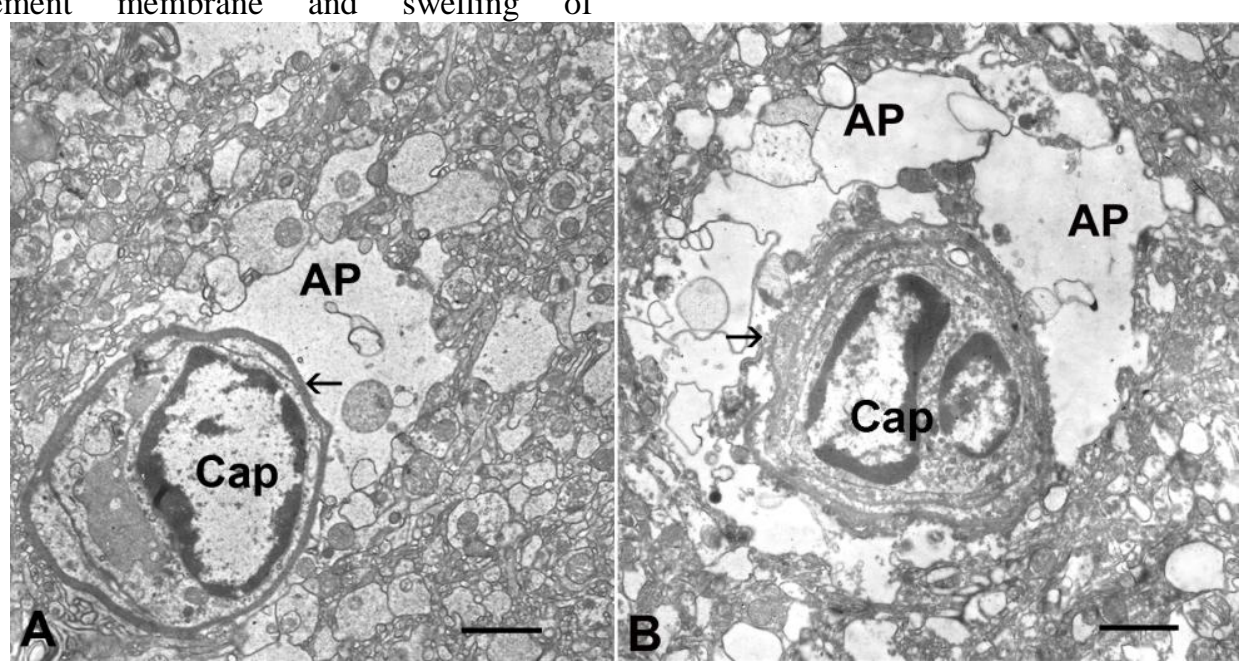

Figure 1. Electron micrographs of capillaries in layer 2 of the prefrontal cortex from control (A) and schizophrenia (B) subjects. Cap - capillary, AP astrocytic process, arrows - capillary basal lamina. Scale bars $=2 \mu \mathrm{m}$

Table 2. Capillary area density (Ncap/mm2) in the prefrontal and visual cortices in the control group, schizophrenia group and in different schizophrenia subgroups (mean \pm SEM)

\begin{tabular}{|c|c|c|c|c|c|}
\hline $\begin{array}{c}\text { Brain } \\
\text { structure }\end{array}$ & Control group & $\begin{array}{c}\text { Schizophrenia } \\
\text { group }\end{array}$ & SPPS & SPNS & $\begin{array}{c}\text { Nonparanoid } \\
\text { schizophrenia }\end{array}$ \\
\hline $\begin{array}{c}\text { Prefrontal } \\
\text { cortex }\end{array}$ & $252.6 \pm 13.4$ & $191.5 \pm 10.8$ & $214.7 \pm 13.7$ & $164.3 \pm 14.1$ & $182.1 \pm 18.7$ \\
\hline $\begin{array}{c}\text { Visual } \\
\text { cortex }\end{array}$ & $186.44 \pm 12.6$ & $182.8 \pm 14.5$ & $192.4 \pm 21.6$ & $171.7 \pm 19.4$ & $196.4 \pm 13.6$ \\
\hline
\end{tabular}

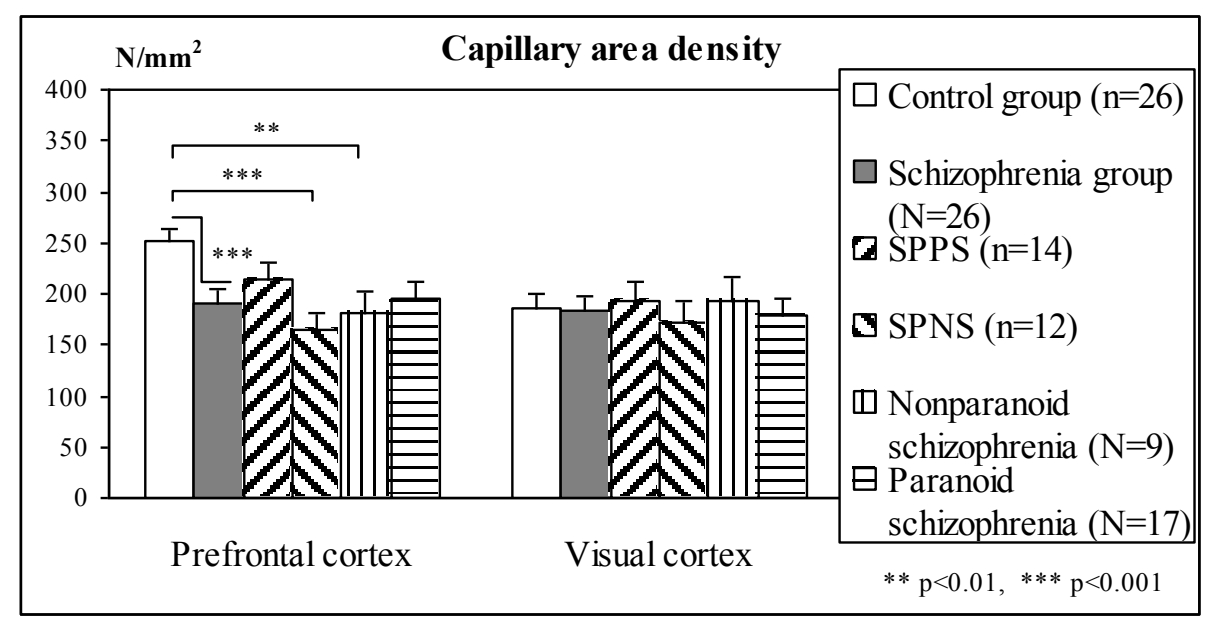

Figure 2. Capillary area density (means \pm SEM) in the prefrontal cortex and in the visual cortex in control group, schizophrenia group, in the subgroup with predominantly positive symptoms (SPPS), in the subgroup with predominantly negative symptoms (SPNS) and in the subgroups of nonparanoid and paranoid schizophrenia 
When the control group and clinical subgroups were compared, the subgroups of schizophrenia subjects with predominantly negative or positive symptoms differed significantly from the control group in the prefrontal cortex $(\mathrm{F}=8.99$, df $=2,49, \mathrm{p}=0.0005)$. Post hoc analysis demonstrated a significantly decreased capillary area density in the subgroup with predominantly negative symptoms $(\mathrm{n}=12,-35 \%, \mathrm{p}<0.0003)$ as compared to the control group (Figure 2). Capillary density tended to decrease in the prefrontal cortex in the schizophrenia subgroup with predominantly positive symptoms as compared to control group, however the decrease did not reach significance $(n=14,-15 \%, p=0.08)$. Comparison of the control group with the subgroups of paranoid and nonparanoid schizophrenia demonstrated that capillary area density differed significantly in the prefrontal cortex $(\mathrm{F}=6.33, \mathrm{df}=2,49, \mathrm{p}=0.003)$. Post hoc analysis revealed that the nonparanoid subgroup had significantly lower capillary density as compared to the control group $(\mathrm{n}=9$, $-28 \%, p=0.005$ ) (Figure 2). No significant differences in capillary area density were found between groups or between schizophrenia subgroups and the control group in the visual cortex ( $p>0.7)$ (Figure 2).

Overall, no effects of postmortem delay, age, age at disease onset, duration of schizophrenia or chlorpromazine equivalents on the parameter measured were found. In addition, no effect of gender on capillary area density was revealed.

\section{Discussion}

To our knowledge, this study is the first electron microscopic morphometric study of blood capillary density in schizophrenia. We used electron microscopic morphometric method because previously we reported significant ultrastructural alterations of capillaries in the same brain structures and in the same brain samples in schizophrenia as compared to controls [25]. The present study provides evidence for region-specific capillary deficit (by 24\%) in the upper layers of the prefrontal cortex, but not in the visual cortex in schizophrenia as compared to controls. Previously we reported that capillary diameter was not changed in schizophrenia patients [25], and the data is in agreement with the results of stereological study of Sinka et al.[28], who showed that capillary diameter was not changed in the anterior cingulate cortex in schizophrenia patients. So capillary size could not influence the estimation of capillary area density. Reduced capillary density cannot be explained by the effects of aging since the control and schizophrenia groups were matched by age and postmortem delay, and these variables did not correlate with capillary area density in either group. No effects of chlorpromazine equivalents on capillary area density were found. These findings are in line with the results of in vivo studies demonstrating that while the atypical neuroleptic clozapine can improve negative symptoms and cognitive dysfunctions, it cannot improve reduced blood flow in the frontal lobes [29]. Both antipsychotics and antidepressants are known to increase proliferation of neuronal and endothelial cells in the hippocampus [30]. Together these data suggest that reduced capillary density found in the prefrontal cortex in schizophrenia is not attributable to the effects of neuroleptic medication.

Kreszmanski and colleagues [16] found no differences in mean capillary length densities in the prefrontal BA 9 in schizophrenia subjects as compared to normal controls in a light microscopic morphometric stereological study. The absence of differences in mean capillary length densities in the prefrontal BA 9 in schizophrenia does not directly contradict the regional and layer-specific reduction of capillary area density found in the upper layers of the prefrontal BA 10 in the present study. Our data is consistent with other abnormalities reported in schizophrenia patients: decreased number of capillary loops by biomicroscopy of the bulbar conjunctiva and capillaroscopy [18], atypical simplified angioarchitecture in orbitofrontal cortex in paranoid hallucinatory schizophrenia patients, and abnormal arborization of the brain vessels [20].

When the subgroups of cases with predominantly positive and negative symptoms were analyzed at separately, capillary area density was significantly $35 \%$ lower in the subgroup with predominantly negative symptoms in the prefrontal cortex as compared to controls and nonsignificantly (15\%) lower in the subgroup with predominantly positive symptoms. The data are in good agreement with the results of our previous studies demonstrated a significant $22 \%$ deficit of pericapillary oligodendrocytes in the prefrontal BA 10 in the schizophrenia group, including a $20 \%$ deficit of pericapillary oligodendrocytes in the subgroup of subjects with predominantly negative symptoms as compared to normal controls [22]. Importantly, our data are also in accordance with a significantly (by 24\%) lower number of neurons in layer 2 of the prefrontal cortex [31], as well as decreased expression of the GAD67 protein, reelin mRNA, and density of reelin-immunopositive neurons in layer 1 of the prefrontal cortex [32] reported in schizophrenia. In addition, nonparanoid subgroups showed significantly lower capillary density as compared to the control group.

We found no significant changes in the capillary area density in the visual cortex in schizophrenia as compared to controls. Previously we reported a decreased synaptic size in layers 1 and 2 in the prefrontal cortex but not in the visual cortex [33] and a significant decrease in numerical density of axospinous synapses in layer 1 of the prefrontal cortex [31]. Moreover, reduced synaptophysin immunoreactivity has been reported in the prefrontal cortex but not in the visual cortex in schizophrenia [34]. Together these data provide evidence that the regionally specific reduction in capillary area density in the prefrontal cortex found in schizophrenia is related to the disease.

It is of interest to note that the aging-related loss of synapses in the prefrontal BA 46 but not in the visual BA17 showed a significant correlation with behavioral measures of memory function in monkeys [35,36]. Since the prefrontal cortex has a greater role in cognition than the primary visual cortex, these data suggest that the deficit of synapses in layer 1 and decreased synaptic size in the upper layers of the prefrontal cortex might be associated with cognitive disturbances and microvascular abnormalities found in schizophrenia. Deficits in capillary density might reduce cerebral blood flow and metabolic support to neurons, and these abnormalities might be 
associated with the capillary damage in subjects with schizophrenia.

The present findings are also in accordance with imaging data suggesting that negative symptom profile in schizophrenia patients displays cognitive deficits and lower cerebral blood flow in the frontal lobes [11,12,14], as well as with the reported negative correlation of negative symptoms with regional cerebral blood flow in the left frontal lobe [13]. Taken together with our results, these data support the notion that the abnormal capillaries revealed in the prefrontal cortex in schizophrenia might reduce cerebral blood flow and consequently result in deficit of metabolic support to neurons. In addition, these abnormalities might also contribute to reduced blood flow and thus might be involved in the production of negative symptoms and cognitive disturbances in schizophrenia.

In vivo studies demonstrated that regional cerebral blood flow abnormalities in patients with chronic schizophrenia do not directly correlate with the illness duration or the effects of medication. Lower blood flow in frontal cortex is already present at the early stage of schizophrenia, suggesting that a similar neural dysfunction occurs in both first-episode and chronic schizophrenia $[37,38,39]$. While microvascular density in each brain region could be genetically programmed, the developmental mechanisms controlling vasculature growth should be dynamic, because changes in neural activity during development are known to result in changes in microvascular density [40]. Capillary density appears to develop in accordance with local functional demands [41]. Increase in metabolic demand produces significant growth of new capillaries, while decreased activity reduces vascular growth $[42,43,44,45]$. Decreased VEGF mRNA expression has been recently reported in the dorsolateral prefrontal cortex of schizophrenia subjects [24]. The development of cortical vascularization is mediated by VEGF [45]. VEGF significantly influence angiogenesis and microvascular plasticity by stimulating neovascularization and increasing the number of blood vessels. VEGF influences neurogenesis, it is involved in the regulation of blood flow and has both neurotrophic and neuroprotective properties [46]. These data suggest that reduced capillary density might be of neurodevelopmental origin.

Significant ultrastructural alterations of capillaries in the prefrontal and visual cortices were found in schizophrenia compared to normal controls in our previous study of the same brain samples [25]. Abnormalities of capillaries and of their microenvironment in schizophrenia brain included thickening, deformation, vacuolation of basal lamina, prominent swelling and vacuolation of astrocytic end-feet, alterations of pericapillary oligodendrocytes and signs of activation of microglial cells. Alterations in microvessel ultrastructure could potentially contribute to changes in both blood flow and transport of materials across the capillary wall. Reduced frontal blood flow during task performance and incapacity to increase blood flow velocity during the time course of cognitive activation compared to control subjects have been reported $[47,48,49]$. These data suggest that the ultrastructural capillary abnormalities and deficiency in the prefrontal cortex in schizophrenia might contribute to hypofrontality, reduced blood flow reported in the prefrontal cortex in schizophrenia.
Altered hemodynamics may lead to hypoactivation [5,9,10,13,37], altered metabolic rates [7] and atrophy of neurons and synapses [33,50,51,52] reported in the prefrontal cortex in schizophrenia. Capillary loss has been reported in the white matter in vascular dementia in leukoaraiosis [53], decreased vascular density has been found in Alzheimer's disease, and cerebrovascular dysfunction precedes and accompanies cognitive dysfunction and neurodegeneration [54]. These data suggest that capillary abnormalities in the prefrontal cortex in schizophrenia detected in the present study might contribute to cognitive impairments in schizophrenia patients.

The limitations of the study are that we did not use stereological methods, and the groups were not gender matched. Future studies of blood capillaries in different brain regions in schizophrenia are required, taking into account the importance of region-specific reduction in the capillary density in schizophrenia reported in the present study.

\section{Conclusions}

Reduced capillary area density found in the prefrontal cortex in schizophrenia could be related to the dysfunction of neocortical microvasculature in schizophrenia. Decreased capillary area density in the prefrontal cortex but not in the visual cortex was most prominent in subjects with predominantly negative symptoms, which is in line with the results of neuroimaging studies. Capillary deficiencies in the prefrontal cortex might contribute to lower blood flow, reduced glucose metabolic rates, resting hypofrontality and hypoactivation detected in the prefrontal cortex of patients with schizophrenia.

\section{Acknowledgment}

This study was supported by the McDonnell Foundation. The authors express their gratitude to Professor William T. Greenough for the helpful discussion of the study.

\section{Statement of Competing Interests}

The authors have no competing interests.

\section{References}

[1] Weinberger, D.R., Berman, K.F. and Zec, R.F. "Physiology dysfunction of dorsolateral prefrontal cortex in schizophrenia. I. Regional cerebral blood flow evidence," Arch Gen Psychiatry, 43(2).114-124. Feb 1986.

[2] Parellada, E., Catafau, A.M., Bernardo, M., Lomena, F., Catarineu, S. and González-Monclús, E., "The resting and activation issue of hypofrontality: a single photon emission computed tomography study in neuroleptic-naive and neuroleptic-free schizophrenic female patients," Biol Psychiatry, 44(8).787-790.Oct 1998.

[3] Ragland, J.D., Gur, R.C., Glahn, D.C., et al. "Frontotemporal cerebral blood flow change during executive and declarative memory tasks in schizophrenia: a positron emission tomography study," Neuropsychology, 12(3).399-413.Jul 1998.

[4] Moreno-Iniguez, M., Ortuño, F., Arbizu, J., Millán, M., Soutullo, C. and Cervera-Enguix, S., "Regional cerebral blood flow SPECT 
study, at rest and during Wisconsin Card Sorting Test [WCST] performance, in schizophrenia naive patients or treated with atypical neuroleptics," Actas Esp Psiquiatr, 33(6).343-351.NovDec 2005.

[5] Andreasen, N.C., Calarge, C.A. and O'Leary, D.S., "Theory of mind and schizophrenia: a positron emission tomography study of medication-free patients," Schizophr Bull, 34(4).708-719.Jul 2008.

[6] Potkin, S.G., Alva, G., Fleming, K., et al. "A PET study of the pathophysiology of negative symptoms in schizophrenia. Positron emission tomography," Am J Psychiatry, 159(2).227-237. Feb 2002.

[7] Buchsbaum, M.S., Nenadic, I., Hazlett, E.A., et al. Differential metabolic rates in prefrontal and temporal Brodmann areas in schizophrenia and schizotypal personality disorder. Schizophr Res, 54 (1-2). 141-150. Mar 2002.

[8] Hoshi, Y., Shinba, T., Sato, C. and Doi, N., "Resting hypofrontality in schizophrenia: A study using near-infrared timeresolved spectroscopy," Schizophr Res, 84 (2-3).411-420.Jun 2006.

[9] Vita, A., Bressi, S., Perani, D., Invernizzi, G., Giobbio, G.M. Dieci, M. Garbarini, M., Del Sole, A. and Fazio, F., "Highresolution SPECT study of regional cerebral blood flow in drugfree and drug-naive schizophrenia patients," Am J Psychiatry, 152 (6).876-882. Jun 1995.

[10] Suzuki, M., Nohara, S., Hagino, H., Takahashi, T., Kawasaki, Y., Yamashita, I., Watanabe, N., Seto, H. and Kurachi, M., "Prefrontal abnormalities in patients with simple schizophrenia: structural and functional brain-imaging studies in five cases," Psychiatry Res, 140 (2).157-171.Nov 2005.

[11] Wang, C.S., Yang, Y.K., Chen, M., Chiu, N.T., Yeh, T.L. and Lee, I.H., "Negative symptoms and regional cerebral blood flow in patients with schizophrenia: a single photon emission computed tomography study," Kaohsiung J Med Sci, 19 (9).464-469.Sep. 2003.

[12] Gonul, A.S., Kula, M., Eşel, E., Tutuş, A. and Sofuoglu, S., "A Tc-99m HMPAO SPECT study of regional cerebral blood flow in drug-free schizophrenia patients with deficit and non-deficit syndrome," Psychiatry Res, 123 (3).199-205. Jul 2003.

[13] Li, X., Tang, J., Wu, Z., Zhao, G., Liu, C. and George, M.S. "SPECT study of Chinese schizophrenia patients suggests that cerebral hypoperfusion and laterality exist in different ethnic groups," World J Biol Psychiatry, 6 (2).98-106.2005.

[14] Zhao, J., He, X., Liu, Z. and Yang, D., "The effects of clozapine on cognitive function and regional cerebral blood flow in the negative symptom profile schizophrenia," Inl J Psychiatr Med, 36 (2).171-81.2006.

[15] Hanson, D.R. and Gottesman, I.I., "Theories of schizophrenia: a genetic-inflammatory-vascular synthesis," BMC Medical Genetics, 11.6.7. Feb 2005

[16] Kreczmanski, P., Schmidt-Kastner, R., Heinsen, H., Steinbusch, H.W., Hof, P.R.and Schmitz, C., "Stereological studies of capillary length density in the frontal cortex of schizophrenics," Acta Neuropathol, 109 (5), 510-518. May 2005.

[17] Kreczmanski, P., Heinsen,H., Mantua,V., et al. "Microvessel length density, total length, and length per neuron in five subcortical regions in schizophrenia,". Acta Neuropathol, 117(4). 409-421.Apr 2009.

[18] Kut'ko, I.I., Frolov, V.M., Rachkauskas, G.S., Pavlenko, V.V. and Petrunia, A.M., "Microhemodynamics and energy metabolism in schizophrenia patients," Lik Sprava, 1, 61-65. Jan-Feb 1997. (Russian).

[19] Orlovskaya, D.D. and Solov'eva, Zh.V., "Changes in the ultrafine structure of capillaries of the embryonic brain in the presence of schizophrenia in the mother," Zh Nevropatol Psikhiatr Im S S Korsakova., 76(7),1043-1046. 1976 (Russian).

[20] Senitz, D. and Winkelmann, E., "Neuronal structure abnormality in the orbito-frontal cortex of schizophrenics," J Hirnforsch, 32 (2). 149-158.1991. (German)

[21] Webster, M.J., Knable, M.B., Johnston-Wilson, N., Nagata, K., Inagaki, M. and Yolken, R.H., "Immunohistochemical localization of phosphorylated glial fibrillary acidic protein in the prefrontal cortex and hippocampus from patients with schizophrenia, bipolar disorder, and depression," Brain, Behav Immunol, 15(4), 388-400. Dec 2001.

[22] Vostrikov, V., Orlovskaya, D. and Uranova, N., "Deficit of pericapillary oligodendrocytes in the prefrontal cortex in schizophrenia," World J Biol Psychiatry, 9 (1), 34-42. 2008
[23] Harris, L.W., Wayland, M., Lan, M., et al. "The cerebral microvasculature in schizophrenia: a laser capture microdissection study," PLoS One, 3 (12), e3964. 2008.

[24] Fulzele, S. and Pillai, A., "Decreased VEGF mRNA expression in the dorsolateral prefrontal cortex of schizophrenia subject," Schizophr Res, 115 (2-3), 372-373. Dec 2009.

[25] Uranova, N.A., Zimina, I.S., Vikhreva, O.V., Krukov, N.O., Rachmanova, V.I. and Orlovskaya, D.D., "Ultrastructural damage of capillaries in the neocortex in schizophrenia," World J Biol Psychiatry, 11(3), 567-578. Apr 2010.

[26] Peters, A., The fine structure of the nervous system. The neurons and supporting cells. Philadelphia, London, Toronto: WB Saunders, 1976. 296-302.

[27] Davis, J.M., Dose equivalence of the antipsychotic drugs. $J$ Psychiatr Res 11, 65-69. 1974

[28] Sinka, L., Kovari, E., Santos, M., Herrmann, F.R., Gold, G., Hof, P.R., Bouras, C. and Giannakopoulos, P., "Microvascular changes in late-life schizophrenia and mood disorders: stereological assessment of capillary diameters in anterior cingulate cortex". Neuropathol Appl Neurobiol, 38(7):696-709. Dec 2012.

[29] Ertugrul, A., Volkan-Salanci, B., Basar, K., et al., "The effect of clozapine on regional cerebral blood flow and brain metabolite ratios in schizophrenia: relationship with treatment response," Psychiatry Res, 174 (2), 121-129.Nov 2009.

[30] Newton, S.S. and Duman, R.S., "Neurogenic actions of atypical antipsychotic drugs and therapeutic implications," CNS Drugs, 21 (9), 715-725. 2007.

[31] Uranova, N.A., Vikhreva, O.V., Zimina, I.S., et al. "Abnormal patterns of cortical synaptic connectivity in schizophrenia," Vest. Ross. Akad. Med. Nauk, 3. 8-14.2007 (Russian).

[32] Guidotti, A., Auta, J., Davis, J.M., et al. "Decrease in reelin and glutamic acid decarboxylase67 (GAD67) expression in schizophrenia and bipolar disorder: a postmortem brain study," Arch Gen Psychiatry, 57 (11), 1061-1069. Nov 2000.

[33] Uranova, N., Orlovskaya, D., Zimina, I., Vikhreva, O., Rachmanova, V., Klintsova, A., Black, J. and Greenough, W.T., "Decreased synaptic size in schizophrenic cortex: a postmortem morphometric electron microscopic study," 30th Annual Meeting of the Society for Neuroscience Abstracts 26: 1558-1558. 2000.

[34] Glantz, L.A. and Lewis, D.A., "Reduction of synaptophysin immunoreactivity in the prefrontal cortex of subjects with schizophrenia. Regional and diagnostic specificity," Arch Gen Psychiatry, 54 (10), 943-952. Oct 1997.

[35] Peters, A., Moss, M.B. and Sethares, C., "The effects of aging on layer 1 of primary visual cortex in the rhesus monkey," Cereb Cortex, 11 (2), 93-103. Feb 2001.

[36] Peters, A., Sethares, C. and Luebke, J.I., "Synapses are lost during aging in the primate prefrontal cortex," Neurosci, 152 (4) 970-981. Apr 2008.

[37] Andreasen, N.C., O'Leary, D.S., Flaum, M., Nopoulos, P., Watkins, G.L., Boles Ponto, L.L. and Hichwa, R.D., "Hypofrontality in schizophrenia: distributed dysfunctional circuits in neuroleptic-naive patients," Lancet, 349 (9067). 17301734.Jun 1997.

[38] Schultz, S.K., O'Leary, D.S., Boles Ponto, et al. "Age and regional cerebral blood flow in schizophrenia: age effects in anterior cingulate, frontal, and parietal cortex," J Neuropsychiatry Clin Neurosci, 14 (1).19-24.Winter 2002.

[39] Kanahara, N., Shimizu, E., Sekine, Y., et al. "Does hypofrontality expand to global brain area in progression of schizophrenia?: a cross-sectional study between first-episode and chronic schizophrenia," Prog Neuropsychopharmacol Biol Psychiatry, 33 (3), 410-415. Apr 2009.

[40] Sonntag, W., Eckman, D., Ingraham, J. and Riddle, D., Regulation of Cerebrovascular Aging, In: Riddle DR, editor. Brain Aging: Models, Methods, and Mechanisms. Boca Raton (FL], CRC Press, 2007, Chapter 12.

[41] Kuschinsky, W. and Paulson, O.B., "Capillary circulation in the brain," Cerebrovasc Brain Metab Rev, 4 (3), 261-286. 1992.

[42] Black, J.E., Sirevaag, A.M. and Greenough, W.T., "Complex experience promotes capillary formation in young rat visual cortex," Neurosci Lett, 83 (3).351-355. Dec1987.

[43] Sirevaag, A.M. and Greenough, W.T., "Differential rearing effects on rat visual cortex synapses. III. Neuronal and glial nuclei, boutons, dendrites, and capillaries," Brain Res, 424 (2). 320-332. Oct 1987. 
[44] Argandoña, E.G. and Lafuente, J.V., "Effects of dark-rearing on the vascularization of the developmental rat visual cortex," Brain Res, 732 (1-2), 43-51.Sep1996.

[45] Argandoña, E.G. and Lafuente. J.V., "Influence of visual experience deprivation on the postnatal development of the microvascular bed in layer IV of the rat visual cortex," Brain Res, 855 (1)137-142.Feb 2000.

[46] Greenberg,D.A. and Jin, K., "From angiogenesis to neuropathology," Nature, 438 (7070), 954-959. Dec 2005.

[47] Higashima, M., Kawasaki, Y., Urata, K., et al. "Regional cerebral blood flow in male schizophrenic patients performing an auditory discrimination task," Schizophr Res, 42 (1), 29-39. Mar 2000.

[48] Crespo-Facorro, B., Paradiso, S., Andreasen, N.C., et al. "Neural mechanisms of anhedonia in schizophrenia: a PET study of response to unpleasant and pleasant odors," JAMA, 286 (4). 427 435. Jul 2001.

[49] Sabri, O., Owega, A., Schreckenberger, M., et al. "A truly simultaneous combination of functional transcranial Doppler sonography and $\mathrm{H}[2][15] \mathrm{O}$ PET adds fundamental new information on differences in cognitive activation between schizophrenics and healthy control subjects," J Nucl Med, 44 (5), 671-681. May 2003.

[50] Selemon, L.D., Rajkowska, G. and Goldman-Rakic, P.S "Abnormally high neuronal density in the schizophrenic cortex. A morphometric analysis of prefrontal area 9 and occipital area 17". Arch Gen Psychiatry, 52 (10). 805-818. Oct 1995.

[51] Selemon, L.D., Rajkowska, G. and Goldman-Rakic, P.S., "Elevated neuronal density in prefrontal area 46 in brains from schizophrenic patients: application of a three-dimensional, stereologic counting method," J Comp Neurol, 392 (3), 402-412. Mar1998.

[52] Black, J.E., Kodish, I.M, Grossman, A.W, et al. "Pathology of layer V pyramidal neurons in the prefrontal cortex of patients with schizophrenia," Am J Psychiatry, 161(4), 742-744.Apr 2004.

[53] Brown, W.R., Moody, D.M., Thore, C.R., Challa, V.R. and Anstrom, J.A., "Vascular dementia in leukoaraiosis may be a consequence of capillary loss not only in the lesions, but in normal-appearing white matter and cortex as well," J Neurol Sci, 257 (1-2), 62-66. Jun 2007.

[54] Brown, W.R. and Thore, C.R., "Review: cerebral microvascular pathology in ageing and neurodegeneration," Neuropathol Appl Neurobiol, 37 (1), 56-74. Feb 2011. 